\title{
A Preliminary Study of Business Student Perceptions of Online VERSUS FACE-TO-FACE EdUCATION
}

\author{
Lynn A. Fish and Coral R. Snodgrass
}

Lynn A. Fish and Coral R. Snodgrass are Professors of Management, Richard J. Wehle School of Business, Canisius College

\begin{abstract}
As institutions of higher education continue to integrate online education into their curricula, the research on student perceptions of the value of online vs. face-to-face courses has produced mixed results. This project identified a number of dimensions used to assess the value of online versus face-to-face courses and measured this in a population of undergraduate and graduate business students. Our results, while also mixed, indicate some important differences in the perceived value of various education formats. These results have implications for both administrators and instructors.
\end{abstract}

Keywords: Student Perceptions, Online, Face-to-face

DOI: http://dx.doi.org/10.15239/j.brcacadje.2014.04.01.ja01 


\section{Literature Review: Dimensions of DIFFERENCE}

Recent research highlights the increase in online education throughout the higher education system (Allen \& Seamen, 2013). As technology continues to change and online methods evolve, research on student perceptions in the online learning environment continues (e.g. Allen \& Seaman, 2013; Perreault, Waldman, Alexander \& Zhao, 2008; Tanner, Noser, Fuselier \& Totaro, 2004-1; 2004-2). Through a literature review, two streams emerge: studies on student characteristics (such as age, gender or familiarity with online courses) and program characteristics (such as academic rigor or the ease of cheating). We examined these two different sets of literature and incorporated salient features of both in our methodology.

\section{Student Characteristics}

Student perceptions regarding the online learning experience should be realistic (Tanner, Noser \& Totaro, 2009), and student emotions impact upon a student's ability to learn. In traditional face-to-face (FTF) classrooms, instructors recognize, react to perceived emotional states and modify their lessons to help students toward positive learning experiences (Reilly, Gallager-Lepak, \& Killion, 2012). Obviously, this cannot exist in today's online environment. Studies that analyze online and FTF student perceptions are mixed, and results often conflict with other studies.

Age. Some research indicates that age impacts upon student perceptions of online (Tanner et al., 2004-1, 2004-2), while others indicate that it does not (Tanner et al., 2003). A more favorable perception of online learning exists for adults (21 and older) than younger students (Tanner et al., 2003).

Major / Level. Business and non-business students differ in their perceptions (Tanner et al., 2004-1; 2004-2). Undergraduate and graduate nursing (Billings, Skiba \& Connors, 2005) and criminal justice (Dobbs 
et al., 2009) students' online perceptions differ. Graduate students may spend more time on their courses, need more instructor attention and find faculty availability to be less satisfactory compared to undergraduates.

Gender. Research on gender perceptions are mixed as some indicate no difference (Tanner et al., 2003) but others indicate a difference (Tanner et al., 2004-1; 2004-2). Recently, no gender differences were reported in self-efficacy, but Internet competencies tend to be significant and favor males (Tekinarslan, 2011).

Previous Experience. Theoretically, the more someone is exposed to and uses a particular technology or method, the more adept they become (Tanner et al., 2003; Tekinarslan, 2011; Dobbs et al., 2009). Similarly, students with prior online experience perceived online courses more favorably than those who did not (Tanner et al., 2003). As the number of online courses increases, the students' acceptance of online courses increases and students' perceive faculty to have higher expectations; however, completing at least 5 online courses are necessary for students to perceive that they learn more in the online environment than FTF (Dobbs et al., 2009). Students not taking online courses perceive that faculty have low expectations of online students, contrary to online students that perceive instructors as having higher expectations. With respect to prior online training, earlier research favored training or tutorials for online students prior to enrollment (Perreault, Waldman, Alexander, \& Zhao, 2002); however, recently, students without online training felt they were adequately prepared (Perreault et al., 2008). While expressing concerns about rise in online courses (Tanner et al., 2006), graduates also grew to accept online education as being equal to or better than traditional FTF (Perrault et al., 2008). Over 8 years, students' perceptions changed as course activities and student interactions with others were satisfied (Mortagy \& Boghikian-Whitby, 2010).

Student Motivation and Commitment. Some studies indicate that student motivation and self-esteem increase in the online environment 


\section{The BRC Academy Journal of Education Vol. 4, No. 1}

(Kearsley, 1998), while another indicates it decreases (Maltby \& Whittle, 2000). Online commitment issues include: students must possess greater discipline in order to succeed, and teachers require considerably greater time and effort (Allen \& Seaman, 2013). Only students with a high degree of autonomy are likely to succeed in a highly structured course with minimal interaction (Wang \& Morgan, 2008). Online courses have high dropout rates in most courses (Carr, 2000). Studies on time commitment perceptions are mixed as online students perceive online to be more time consuming (Perreault et al., 2008; Dobbs et al., 2009), while others find FTF students report studying more than their online counterparts (Horspool \& Lange, 2012).

\section{Program Characteristics}

Program characteristics impact upon student perceptions too. Barriers to distance education include: faculty, organization and course structure; physical distance; difficulties in dealing with media; time constraints; lack of background knowledge, distance education experience or technology skills; and low interactivity with the communication process (Olesova, Yang \& Richardson, 2011). Program characteristic research also produced mixed results.

Course Organization. Students perceive the course organization - particularly the learning environment structure and online assessment, as key to student learning and success (Armstrong, 2011). Studies report student distress with online learning with ambiguous instructions (Perreault et al., 2008). Research favors research-based validated online frameworks with benchmarks and favors a student-centered model (Mortagy \& Boghikian-Whitby, 2010). Students choosing to take online courses typically cite flexibility and convenience (Horspool \& Lange, 2012; Perreault et al., 2008), the ability to self-control the learning environment (Armstrong, 2011), avoiding a commute to campus, and work demands (Horspool \& Lange, 2012). 
Academic Rigor. Student perceptions on academic rigor vary, with some studies finding FTF courses easier than online (Dobbs et al, 2009), while other finding online courses easier than FTF (Armstrong, 2011). In sub-Sahara Ghana, students perceived collaborative online learning as complex, more demanding and time-consuming than FTF (Asunka, 2008).

Program Quality. Chief academic officers claim that online learning is now of the same quality as traditional courses (Allen \& Seaman, 2013). However, student quality perceptions are mixed as some favor online over FTF (Hannay \& Newvine, 2006), while others indicate the opposite (Asunka, 2008). Students with prior experience felt online quality was comparable, but first-time online students felt online quality was lower (Dobbs et al., 2009).

Academic Integrity. Rumors surrounding online cheating abound. Generally, most feel students are more inclined to cheat in the online environment. In a criminal justice course survey on FTF versus online student perceptions, most students felt cheating is more common online but most indicated they never cheated (Lanier, 2006). Online students (40\%) admitted assisting others with exams, and many good students felt they had to cheat to be competitive with others who they felt were cheating (Lanier, 2006). Students with higher gpa's, females, married and older students are less inclined to cheat (Lanier, 2006).

Communication Mechanisms. Communication speed and consistency is shaping students' perceptions and approaches to learning (Armstrong, 2011). Result are mixed as some studies indicate online courses enhance learner participation and interactivity (Maeroff, 2004), and others highlight student distress (Hara \& Kling, 2003) or general feeling of 'disconnect' due to the lack of FTF interactions (Stodel, Thompson \& MacDonald, 2006). Online students who do not perceive that they are part of the group report less quality student communication (Horspool \& Lange, 2012), a lack of student interaction and a general unwillingness of other online learners to participate in group assign- 
ments (Maeroff, 2004). Online students interaction may be less (Horspool \& Lange, 2012) or more (Wang \& Morgan, 2008) than FTF.

Faculty Involvement. When students perceive faculty as missing from the conversation, students perceived the course quality as poor and vice versa (Armstrong, 2011). Mixed results exist as some studies indicate that online interaction with the instructor is equal or even more positive than FTF (Boyd, 2008), indifferent (Horspool \& Lange, 2012) or weaker (Wang \& Morgan, 2008). Online students may perceive faculty as being available to communicate, interact and provide feedback (Mortagy \& Boghikian-Whitby, 2010).

Technologies. Online offers greater access to additional learning resources (Sener \& Stover, 2000) but requires additional student and instructor skills (Tekinarslan, 2011). Technically, online and FTF students appear technically well-equipped and comfortable in taking online courses as few report significant communication issues (Hospool \& Lange, 2012). Students perceive a tool's value by how it's implemented, and the negative technology attributes are not as important as the communication quality (Armstrong, 2011). Unfortunately, faculty weak in technology appear to utilize technology in a manner that creates confusion (Armstrong, 2011). Students utilize nonacademic resources more readily than academic resources in completing assignments (Armstrong, 2011). Most used and valued elements include accessing unit information, accessing lecture/lab notes, interacting with unit learning resources, reading online discussions, contacting lecturers/tutors and submitting assignments online (Palmer \& Holt, 2010). Students felt receiving feedback on assignments and reviewing unit progress as needing attention (Palmer \& Holt, 2010). Students perceived video modules, quizzes and the textbook as valuable to the learning environment regardless of online or FTF (Horspool \& Lange, 2012). Instant messaging may be used as a technique to increase dialogue and reduce distance between students in an online course (Wang \& Morgan, 2008). 


\section{SAlient Conclusions for OUR Study}

While not comprehensive, this literature review clearly indicates that ambiguity currently exists in the debate between online and FTF education. Some research favors FTF over online (Mullen \& Tallent-Runnels, 2006), online over FTF (Connolly, MacArthur, Standfield \& McLellan, 2007) or indifference (Horspool \& Lange, 2012). Studies differ in the size (small, medium, large universities), audience (e.g. scientific versus social sciences, business versus non-business, and graduate versus undergraduate), and method of research (e.g. interview, survey). Thus, the study's context may be an important factor to consider. Most business student perceptions research was published over 5 years ago (e.g. Perreault et al., 2008; Tanner et al., 2003; Tanner et al., 2004-1, 2004-2), and similar to other studies (Mortagy \& Boghikian-Whitby, 2010; Perreault et al., 2008), perceptions may have changed.

We conducted our study at a mid-sized, Jesuit, Catholic, business school with a focus on teaching. The research focus lies in uncovering student perceptions where FTF class sizes average 17 students. Online education is a growing educational method; however, not all students have experienced this medium (Allen \& Seaman, 2013). Based upon the literature, the research intent is to explore graduate and undergraduate students' perceptions of the online experience for those with and without online experience at a teaching university. Specifically, this research seeks to explore: Why do students at a teaching university choose online or traditional FTF classes? What are the factors that motivate each group? Which medium do students at a teaching university prefer? Why? Are there perceptual differences between undergraduates and graduates? Are there perceptual differences between genders? Do student's perceptions change as they take more online courses? Specific perceptions to research include perceptions of academic rigor, self-directed learning, motivation, interaction between students and the instructor, discipline required, cheating, flexibility, time investment, costs, and teaching activities preferred. Theoretically, students should 
perceive the environments equally and not favor either traditional or online education.

\section{METHOD}

At an AACSB accredited, Jesuit, Catholic University in the northeast, 3 undergraduate classes and 3 graduate business classes completed the survey. The surveys were administered during the last week of classes and student participation was completely voluntary. The three undergraduate classes, which included a management science, an operations management, and an information systems courses, were all FTF courses. The graduate classes included a FTF global supply chain management course (part-time MBA), a FTF information systems course (full-time $\mathrm{MBA}$ ), and an online masters in international business course. 64 undergraduates and 47 graduates participated in the survey.

Based upon the above research, the instructors designed a survey to test student perceptions of experience levels, gender, academic rigor and self-directed learning, motivation, interaction between students and the instructor, discipline, ability to cheat, flexibility, time investment, cost investment, activities, activity preferences, and why students choose the online environment. (The survey is available upon request from the authors). Background information gathered included class level, gender and online experience. Students who experienced at least 1 online course completed Section A ("Online"), while students who had never taken an online course completed Section B ("Traditional FTF"). Sections A and B had corresponding questions, but Section A statements were specific to "I found" versus Section B statements were "I perceive". The last questions in each section asked the student if they would prefer the opposite environment, their emotional happiness with the learning environment, and whether online courses were appropriate for the institution. For students with online experience, the last question inquired why they 
chose to take an online course. For students without online experience, the survey included an open-ended question inquiring 'why not'.

Information from the surveys was codified as Significantly Less (1), Less (2), The Same (3), More (4) and Significantly More (5), and the data was entered into an EXCEL spreadsheet for preliminary analysis.

\section{Analysis}

\section{Overall Comparison Online vs. Traditional Student Perceptions}

As shown in Table 1, Section A, student preferences indicate a dislike toward online learning versus FTF learning for difficulty, motivation, student interaction and instructor interaction. Students indicate they perceived cheating to be more likely in online classes than FTF. Online students prefer the discipline, independence and schedule flexibility of online over FTF classes, and are indifferent to self-directed learning, time and cost investment. Most students did not take a preparation course prior to their online experience and took just 1 course prior to completing the survey. Most online students indicate while they were 'okay' with the online experience, they would prefer to be in a FTF classroom. Correspondingly, in Section B, traditional students indicate that they were happy with the FTF classroom and prefer it. Traditional students find the FTF classroom to be difficult, motivational, approved of the self-directed learning environment, and prefer the interaction with students and the instructor. They also feel cheating is more difficult in the traditional environment than online. Traditional students are indifferent to discipline, independent learning, time investment, and cost investment. While the majority of FTF students note that traditional classes do not offer the schedule flexibility that online courses do, almost half feel the scheduling flexibility is similar or better in a traditional classroom. Both groups indicate that online courses are appropriate at the University. 
Tests for significant differences in perceptions between the online students and traditional FTF students (t-test, 2-tails, assuming heteroscedasticity) reveal that the groups significantly differ in their perceptions on many measures. Details for all analyses are available from the authors upon request. Specifically, both groups prefer the difficulty associated with their learning environment $(p=.00)$. However, online students are less motivated online and FTF students are more motivated in FTF environment $(\mathrm{p}=.02)$. As a result, both groups tend to be more motivated in the traditional FTF environment. Both groups tend to prefer the interaction with others $(\mathrm{p}=.00)$ and the instructor $(\mathrm{p}=.00)$ more in traditional FTF classroom. Each group tends to feel the discipline required in their group is 'equal to more' than the other instructional method $(\mathrm{p}=.03)$. Both groups feel online cheating is easier online than in the traditional classroom $(\mathrm{p}=.03)$. Traditional students enjoy the instructor led environment, while online students find the experience to be roughly the same $(p=.00)$. Both groups felt the independent learning was about the same but slightly favored their own learning environment $(\mathrm{p}=.00)$. Students who never tried online courses do not fully perceive the scheduling flexibility afforded online classes, while those who have, perceive its benefits $(\mathrm{p}=.00)$. The majority of FTF students $(56 \%)$ does not wish to try the online environment or are undecided (35\%). While close to half (48\%) online students (most taking fewer than 5 courses) prefer to take a course in a traditional classroom instead or are undecided (41\%). Only 5 (11\%) of the students taking an online course prefer online courses. Both groups tend to prefer FTF courses $(p=.00)$. This result may be due to little online experience. Online students appear to be 'okay' with the experience but do not appear to enjoy it as much as the traditional FTF group $(\mathrm{p}=.00)$. Both groups are indifferent with respect to the time $(\mathrm{p}=.12)$ and cost $(\mathrm{p}=.19)$ investment differences, and feel online courses are appropriate at the University $(\mathrm{p}=.26)$. 


\section{Learning Experience Preferences}

Forty-two students with an equal number of graduates and undergraduates completed Section A. Most online students feel homework (76.19\%), discussion boards (71.43\%), and videos (50\%) are the top three learning activities that increase their academic understanding. They sight in-class sessions (23.81\%), instructor lectures (23.81\%) and other students $(21.43 \%)$ as decreasing their understanding of course material. Undergraduates and graduates are very similar in their viewpoints of homework and discussion boards as the top online activities and in-class sessions and instructor lectures as the main two activities that decrease their understanding.

Sixty-seven students - 42 undergraduates and 25 graduates responded to Section B. Traditional FTF students feel instructor lectures (73.13\%), discussion boards (73.13\%) and in-class sessions $(67.16 \%)$ increase their understanding of material, with undergraduates and graduates similar in their preferences. However, they most frequently sight discussion boards $(22.39 \%)$, in-class sessions (32.84\%), instructor chat $(22.39 \%)$ and reading $(26.87 \%)$ as the activities that decreases in the online environment. Perhaps, traditional students find the interaction with others as the key reason to be in a traditional class versus online. Comparing the two populations, while both groups favor using discussion boards (note this implies FTF used this technology), online students appear to favor different activities than FTF students, who prefer in-class sessions and instructor lectures.

\section{Online Perceptual Differences with Experience}

Student perceptions for online students taking one versus two online courses indicate a few differences. When students take a second online course, their perception of difficulty increases, and they find the difficulty factor to be roughly the same or harder than traditional classes $(p=.03)$. After taking a second course, students find the interaction with other students to significantly improve over traditional courses $(\mathrm{p}=.03)$. Students who experience at least 2 online courses perceive that ability 


\section{The BRC Academy Journal of Education Vol. 4, No. 1}

to cheat is significantly harder online than FTF $(p=.03)$ and are significantly happier than students who only take one online course $(\mathrm{p}=.03)$. Including the students with more than two classes, students perceptions towards online are significantly more positive, including motivation $(\mathrm{p}=.02)$, discipline $(\mathrm{p}=.04)$ and cost investment $(\mathrm{p}=.02)$. These results, particularly the shift in 'happiness', favor the idea that students online perceptions improve as they take more courses.

\section{Undergraduates vs. Graduates}

Undergraduates and graduates do not differ with respect to their responses to either the online or FTF. Graduates dislike the self-directed online environment slightly more than their undergraduate counterparts $(\mathrm{p}=.06)$. While both groups favor the appropriateness of online courses, graduates are slightly more undecided than undergraduates $(\mathrm{p}=.06)$.

\section{Gender}

66 males and 40 females completed the survey. Undergraduate males (36) and graduate males (30) outnumbered undergraduate females (25) and graduate females (15), respectively. Overall differences by gender do not exist with regard to student perceptions of online and FTF. Specific to undergraduates, no gender differences exist in either group with the exception of female FTF students indicate online courses are acceptable to undecided, while males are undecided $(\mathrm{p}=.05)$. For graduates, no gender differences in either group exist except for online males who are significantly happier than online females $(\mathrm{p}=.04)$, and where males feel online is appropriate and females are undecided $(\mathrm{p}=.05)$. Note, while the equal numbers of men (10) and women (10) took online courses, only a third of all males took online courses, while two-thirds of the females did.

\section{Discussion}

The key focus of this study is to evaluate student perceptual differences between online and FTF courses at a business school with a focus 
on teaching. Similar to results for criminal justice students (Dobbs et al., 2009), students without online experience have different perceptions of online learning than those who have. At a mid-sized, Jesuit, AASCBaccredited university in the northeast, student perceptions still favor the FTF experience to online. While online and FTF students indicate that online courses are appropriate at the University, they prefer to be in a traditional classroom. Students chose to take online courses mainly for flexibility reasons (Comments available upon request from authors.). For almost every factor studied (difficulty, motivation, interaction with students, interaction with instructors, discipline, cheating, self-directed, independence, schedule flexibility, time and cost investment), along with their comments regarding taking online courses (Comments available upon request from authors.), traditional students appear to know their learning style and understand their personal need for FTF interaction. The end result may be student self-selection to the learning environment that suits his needs best. So while many online advocates point to the increasing desire for online classes (Allen \& Seaman, 2013), these results indicate that this may not be the case for students with different learning styles. Several previous studies were done at large universities, in a public forum (Horspool \& Lange, 2012; Tanner et al., 2004-1, 2004-2) or in non-business fields (e.g. Dobbs et al, 2009; Lanier, 2006; Tekinarslan, 2011). These results indicate that what the University offers in the FTF environment may be an important construct to consider in developing the online framework. In support of previous research (Dobbs et al., 2009) significant perceptual differences between the students who have and those who have not experienced online education exist. Online perceptions at the University need to be addressed.

As previous studies noted (Dobbs et al., 2009; Mortagy \& BoghikianWhitby, 2010; Perreault et al., 2008), student perceptions improve with increasing exposure to the online environment. Perhaps, since most students in this study only took 1 online course, the students may not have enough online experience, and therefore, still prefer the traditional classroom over online courses. These results support the idea that with 


\section{The BRC Academy Journal of Education Vol. 4, No. 1}

continued experience, students appear to perceive online education more positively.

With respect to learning experiences at the teaching University, online and traditional students favor different learning techniques, which have implications for developing online and FTF frameworks. The University prides itself on, and markets, its teaching atmosphere. Clearly, traditional FTF students value the classroom interaction with the instructor and other students. However, online, these same students prefer the homework, discussion boards, and videos over the more traditional inclass sessions, instructor lectures and other students. Obviously, students favor different teaching methods in each teaching medium.

No significant differences in graduate or undergraduate student perceptions regarding online or traditional FTF learning exist. So in contrast to the nursing students (Billings et al., 2005), graduate and undergraduate students did not differ in the time investment or instructor interaction. Slight differences were detected with regard to the self-directed nature of the online environment, where graduates tend to dislike it more.

Student perceptual gender differences were not noted for undergraduate (supporting Tanner et al., 2003; Tekinarslan, 2011) or graduate students. Studies (Tanner et al., 2004-1; 2004-2) indicating gender differences for business students were conducted over 9 years ago. Perhaps females' perceptions today are more on par with males in the IT environment than previous studies indicate (Tekinarslan, 2011).

Assuming as upper administrators do that online education is equivalent to FTF (Allen \& Seamen, 2013) then students should be indifferent to all of the factors surveyed. The results clearly indicate that this is not the case as business students at a teaching university preferred FTF education. These results support and contrast the previously cited research. For example, with respect to academic difficulty, both groups of business students perceive online to be easier, similar to some research 
(Armstrong, 2011) but contrary to other researchers (Asunka, 2008; Dobbs et al., 2009). In contrast to criminal justice students (Lanier, 2006), business students support the concept that it's easier to cheat in FTF than online. Differences may result from differences in course design between online and FTF courses. Results support a preference for student interaction in FTF (Hara \& Kling, 2003; Horspool \& Lange, 2012) which contrasts with other research (Frederick et al., 2004; Mortagy \& Boghikian-Whitby, 2010). Instructor interaction is favored by the business students, similar to some research (Wang \& Morgan, 2008) but contrary to other research (Horspool \& Lange, 2012). In general, these results support one study, while contrasting another for every factor studied. Thus, other factors impact upon students' perceptions regarding online education and research to uncover these underlying factors is needed. Potential factors such as exploring student learning styles or university contextual factors of size and focus (teaching versus research) may offer a clearer understanding of student online perceptions.

\section{Conclusions}

In a preliminary study at an AACSB, Jesuit, Catholic, university in the northeast with a strong focus on teaching, business student perceptions regarding online versus FTF courses indicate that students prefer FTF classes. Traditional FTF students perceive online education differently than those who experienced both online and FTF. Student apprehensions regarding online education are very apparent. Only $11 \%$ of online students prefer it to traditional education. However, as students acquire more online experience, their perceptions of online education improve. Student responses to difficulty, motivation, discipline, cheating, selfdirected learning, independence, and interaction with the instructor and other students favor FTF education as being preferred. As expected, online students prefer schedule flexibility. Students are indifferent to time and cost investment between the two teaching methods. In the FTF classroom, the interactions with others and the instructor are valuable to 


\section{The BRC Academy Journal of Education Vol. 4, No. 1}

students, while in the online environment, students prefer other learning activities. No significant differences between graduates and undergraduates or males and females exist. Research demonstrates support and opposition to online education, implications for both administrators and instructors, and the potential for other factors that may impact upon students' perceptions regarding online education.

\section{LIMITATIONS}

Two key limitations of this study exist: the fact that most students completed the survey while part of a FTF class, and while the sample sizes are acceptable overall, comparison sample sizes tend to be small. Only one class with a very small population completed the survey as part of an online class. While the questions were posed from both perspectives, the fact that students were sitting in a class while completing it may have clouded their perceptions. Similarly, the comparisons for differences in number of online courses taken included only 13 students taking 2 or more classes. A more robust sample that may be subdivided into relevant subgroups is needed to perform more complex statistical analysis.

\section{FUTURE Research}

Several areas for future research exist including: student learning styles and specific university contextual comparisons, larger sample sizes for number of classes taken, a deeper comparison of teaching populations, course design, and cultural differences. While the discussion highlights the potential for differences due to contextual factors of a teaching university versus larger research universities, a specific study directly comparing business students at one type versus another is lacking. Also, current research does not differentiate between forprofit and not-for-profit institutions of higher education. As the number of students taking more online classes increases, comparisons to the FTF classes in perceptions may be evaluated in finer detail. The current 
curriculum includes part-time students, full-time students and online students. Differences in student perceptions between each of these groups may be explored in greater detail. There are significant differences in course design between online and FTF education and these differences need to be evaluated as well. Also, differences in different cultural perceptions to online versus FTF education are emerging (Olesova et al., 2011). For example, other countries - particularly African countries, perceive online learning as second-rate to FTF and as a result, some countries enacted policies that do not recognize foreign credentials obtained through online courses, sighting problems in quality control and accreditation (Asunka, 2008). Expanding online learning across the globe into different cultures adds potential barriers to online learning that need to be explored (Olesova et al., 2011). Expanding the study to explore other culture's perceptions may yield different results. Other cultural differences, such as individualistic versus collective tendencies (Hornik \& Tupchiy, 2006), need to be evaluated. Team work differences between working in virtual teams and student perceptions exist (Olesova et al., 2011) and need to be explored in greater depth. Hence, much work remains in student online perceptions.

\section{REFERENCES}

Allen, I., \& Seaman, J. (2013). Changing Course: Ten Years of Tracking Online Education in the United States. The Sloan Consortium (SloanC), Retrieved on January 11, 2013 from http://sloanconsortium.org/ publications/survey/making_the_grade_2006

Armstrong, D.A. (2011). Students' Perceptions of Online Learning and Instructional Tools: A Qualitative Study of Undergraduate Students Use of Online Tools. The Turkish Online fournal of Educational Technology - July 2011, 10(3), 222-226.

Asunka, S. (2008). Online Learning in Higher Education in Sub-Saharan Africa: Ghanaian University students' experiences and perceptions. 
International Review of Research in Open and Distance Learning, October 2008, 9(3), 1-23.

Billings, D.M., Skiba, D.J. \& Connors, H.R. (2005). Best Practices in Webbased Courses: Generational Differences Across Undergraduate and Graduate Nursing Students. Journal of Professional Nursing, 21(2), 126-133. http://dx.doi.org/10.1016/j.profnurs.2005.01.002

Boyd, P.W. (2008). Analyzing students' perceptions of their learning in online and hybrid first year composition courses. Computers and Composition, 25, 224-43. http://dx.doi.org/10.1016/j.compcom.2008 .01 .002

Carr, S. (2000). As distance education comes of age, the challenge is keeping the students. Chronicle of Higher Education, 46(23), A39.

Connolly, T.M., MacArthur, E., Stansfield, M. \& McLellan, E. (2007). A quasi-experimental study of three online learning courses in computing. Computers \& Education, 49, 345-59. http://dx.doi.org/1 0.1016/j.compedu.2005.09.001

Dobbs, R., Waid, C.A., \& del Carmen, A. (2009). Students' Perceptions of Online Courses: The Effect of Online Course Experience. Quarterly Review of Distance Education, Spring 2009, 10(1), 9-26.

Hannay, M., \& Newvine, T. (2006). Perceptions of Distance-Learning: A Comparison of Online and Traditional Learning. MERLOT fournal of Online Learning and Teaching, 2(1), 1-11, Accessed on January 11, 2013 from http://jolt.merlot.org/documents/MS05011.pdf

Hara, N., \& Kling, R. (2003). Students' distress with a web-based distance education course: An ethnographic study of participants' experiences. Turkish Online fournal of Distance Education, 4(2), 557-579.

Hornik, S., \& Tupchiy, A. (2006). Culture's impact on technology mediated learning: The role of horizontal and vertical individualism and collectivism. Journal of Global Information Management. 14(4), 31-56. http://dx.doi.org/10.4018/jgim.2006100102

Horspool, A. \& Lange, C. (2012). Applying the scholarship of teaching and learning: student perceptions, behaviors and success online and face-to-face, Assessment \& Evaluation in Higher Education, February 
2012, 37(1), 73-88, Accessed on January 8, 2013 from http://dx.doi. org/10.1080/02602938.2010.496532.

Kearsley, G. (1998). Distance education goes mainstream. falseT.H.E. Journal,25(10),22.

Lanier, M. (2006). Academic Integrity and Distance Learning. Journal of Criminal Justice Education, Sep 2006, 17(2), 244-21. http://dx.doi. org $/ 10.1080 / 10511250600866166$

Maeroff, G.I. (2004). Classroom of one: How online learning is changing our schools and colleges. Gordonsville, VA: Palgrave Macmillan.

Maltby, J. R., \& Whittle, J. (2000). Learning programming online: Student perceptions and performance. Proceedings of the ASCILITE 2000 Conference. Accessed on January 9, 2013 from http://www.ascilite. org.au/conferences/coffs00/papers/john_maltby.pdf

Mortagy, Y. \& Boghikian-Whitby, S. (2010). A Longitudinal Comparative Study of Student Perceptions in Online Education. Interdisciplinary Fournal of E-Learning and Learning Objects, 6, 23-46.

Mullen, G.E., \& Tallent-Runnels, M.K. (2006). Student outcomes and perceptions of instructors' demands and support in online and traditional classrooms. Internet and Higher Education, 9, 257-66. http://dx.doi.org/10.1016/j.iheduc.2006.08.005

Olesova, L., Yang, D. \& Richardson, J.C. (2011). Cross-cultural differences in Undergraduate Students' Perceptions of Online Barriers. fournal of Asynchronous Learning Networks, 15(3), 68-80.

Palmer, S. \& Holt, D. (2010). Students' perceptions of the value of the elements of an online learning environment: looking back in moving forward. Interactive Learning Environments, June 2010, 18(2), 135151. http://dx.doi.org/10.1080/09539960802364592

Perreault, H., Waldman, L., Alexander, M. \& Zhao, J. (2008). Graduate Business Students' Perceptions of Online Learning: A Five Year Comparison. The Delta Pi Epsilon fournal, Fall 2008, L(3), 164-179.

Perreault, H. Waldman, L., Alexander, M. \& Zhao, J. (2002). Overcoming barriers to successful delivery of distance-learning courses. Fournal of Education for Business, 77(6), 313-318. 
Reilly, J.R., Gallager-Lepak, S. \& Killion, C. (2012). Me and My Computer: Emotional Factors in Online Learning, Nursing Education Perspectives, March/April, 33(2), 100 - 105.

Sener, J., \& Stover, M. L. (2000). Integrating ALN into an independent study distance education program: NVCC case studies. Fournal of Asynchronous Learning Networks, 4(2), 126-144.

Stodel, E. J., Thompson, T. L., \& MacDonald, C. J. (2006). Learners' perspectives on what is missing from online learning: Interpretations through the community of inquiry framework. International Review of Research in Open and Distance Learning, 7(3), 1-24. Accessed on January 9, 2013 from http://www.irrodl.org/index.php/irrodl/article/ view/325/743

Tanner, J.R., Noser, T.C., \& Totaro, M.W. (2009). Business Faculty and Undergraduate Students' Perceptions of Online Learning: A Comparative Study. Journal of Information Systems Education, Spring 2009, 20(1), 29-40.

Tanner, J., Noser, T., Totaro, M., \& Birch, R. (2006). Student Perceptions of The Online 'Classroom': An Update. International Business \& Economics Research fournal, 5(10), 31-38.

Tanner, J., Noser, T., Fuselier, J., \& Totaro, M. (2004-1). 'The Online 'Classroom': Differences in Perception between Business Students and Non-Business Students. Journal of College Teaching and Learning, 1(3), 37-44.

Tanner, J., Noser, T., Fuselier, J., \& Totaro, M. (2004-2). 'The Online 'Classroom': What Do Students Think? Journal of Informatics Education Research, 6 (1), 43-54.

Tanner, J., Noser, T., \& Langford, H. (2003). Perceptions of Undergraduate Business Students Toward Online Courses In Higher Education Expanded and Revisited: Do Gender, Age, and/or Past Experiences Make a Difference? Journal of Business and Economics Research, 1(2), 13-20.

Tekinarslan, E. (2011). Faculty of Education Students' Self-efficacy Perceptions toward Online Technologies. Electronic fournal of Social Sciences, Summer 2011, 10(37), 120-134. 
Wang, L.C. \& Morgan, W.R. (2008). Student Perceptions of Using Instant Messaging Software to Facilitate Synchronous Online Class Interaction in a Graduate Teacher Education Course. fournal of Computing in Teacher Education, Fall 2008, 25(1), 15-21.

\section{Web APpendix}

A web appendix for this paper is available at:

http://dx.doi.org/10.15239/j.brcacadje.2014.04.01.wa01

\section{Citation Information}

Fish, Lynn A. and Coral R. Snodgrass. "A Preliminary Study of Online Versus Face-to-Face Education?” The BRC Academy fournal of Business 4, no. 1 (2014): 1-21. http://dx.doi.org/10.15239/j.brcacadje.2014.04.01.ja01 